\title{
Erratum: Differential item functioning of the CESD-R and GAD-7 in African and white working adults
}

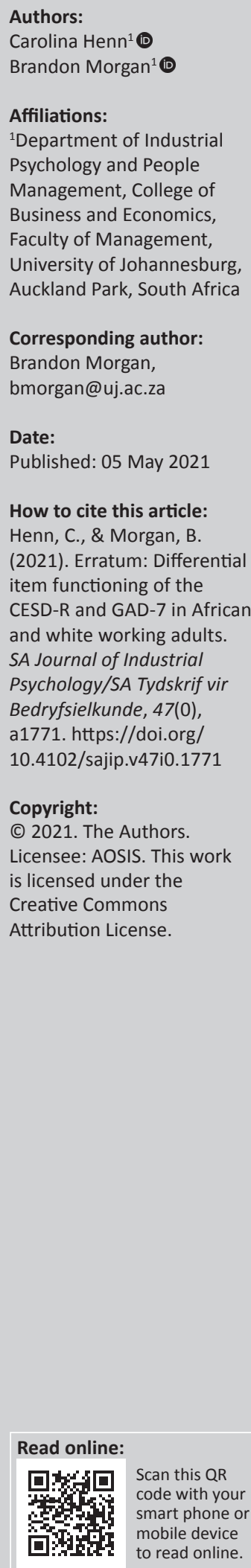

In the version of this article initially published, Henn, C., \& Morgan, B. (2019). Differential item functioning of the CESDR-R and GAD-7 in African and white working adults. SA Journal of Industrial Psychology/SA Tydskrif vir Bedryfsielkunde, 45(0), a1663. https://doi.org/10.4102/sajip. $\mathrm{v} 45 \mathrm{i} 0.1663$ the title of the manuscript has been incorrectly published as 'Differential item functioning of the CESDR-R and GAD-7 in African and white working adults'. The correct title wording is 'Differential item functioning of the CESD-R and GAD-7 in African and white working adults'.

On page 5 of the article, Table 1 is incorrectly displayed without the confidence intervals for the alpha and parameter estimates for the omega columns.

The correct table is presented below:

TABLE 1: Descriptive statistics and reliability coefficients for the Centre for Epidemiological Depression Scale Revised and Generalised Anxiety Disorder 7 scale scores across African and white participants.

\begin{tabular}{lccccccccccc}
\hline Participants & Mean & Mdn. & SD & Skew. & Kurt. & SE & $\boldsymbol{\alpha}$ & $\begin{array}{c}\text { Confidence } \\
\text { intervals }\end{array}$ & $\boldsymbol{\omega}$ & $\begin{array}{c}\text { Parameter } \\
\text { estimates }\end{array}$ & $\boldsymbol{\beta}$ \\
\hline CESD-R African & 15.37 & 11.00 & 14.33 & 1.27 & 1.17 & 0.82 & 0.94 & $0.92,0.95$ & 0.94 & $0.92,0.95$ & 0.69 \\
CESD-R white & 14.04 & 10.00 & 14.29 & 1.87 & 3.90 & 0.92 & 0.95 & $0.93,0.96$ & 0.95 & $0.93,0.96$ & 0.80 \\
GAD-7 African & 5.91 & 4.00 & 5.34 & 0.89 & -0.09 & 0.31 & 0.91 & $0.89,0.93$ & 0.91 & $0.89,0.93$ & 0.86 \\
GAD-7 white & 6.28 & 5.00 & 5.31 & 0.89 & -0.06 & 0.35 & 0.93 & $0.92,0.95$ & 0.93 & $0.92,0.95$ & 0.85 \\
\hline
\end{tabular}

Note: $95 \%$ bootstrapped confidence intervals for coefficient $\alpha$ and $\omega$. CESD-R African: $n=307$; CESD-R white: $n=244$; GAD-7 African: $n=304$; GAD-7 white: $n=225$.

CESD-R, Centre for Epidemiological Depression Scale Revised; GAD-7, Generalised Anxiety Disorder 7-Item Scale; SD, standard deviation; $\mathrm{SE}$, standard error; Mdn., median; Skew., skewness; Kurt., kurtosis; $\beta$, Revelle's coefficient beta.

This correction does not alter the study's findings of significance or overall interpretation of the study's results. The publisher apologises for any inconvenience caused. 